\title{
Eco-physiological responses of invasive and indigenous mytilids in the Ría de Vigo
}

\section{(NW Spain)}

Jose M.F. Babarro $^{1, *}$ and Malwenn Lassudrie ${ }^{2}$

\section{Abstract}

The impact of an alien species is correlated with its abundance and potential to colonise new environments. Consequently, the crucial aspects that give a mytilid species invasive potential include its strength and capacity for adhesion to a wide variety of substrates and its ecological tolerance to environmental conditions. The alien black pygmy mussel Xenostrobus securis settles together with the indigenous and raft cultured mussel Mytilus galloprovincialis on hard substrates of the inner coastline of the Ría de Vigo (NW Spain). Key parameters for the ecological success of these species could include their byssus structure and ecological plasticity. In this study, we assessed their comparative ability to attach to different substrates under different environmental conditions, using both in situ and laboratory approaches.

Byssus threads secreted by $X$. securis were found to be extremely thin and their thickness did not vary with mussel size. This thinness of byssus filaments in $X$. secures was compensated by the secretion of a huge number (up to thousand). Although no increase in attachment strength was found with increasing mussel size in this species, multiple byssus thread secretion might be a key factor in the successful invasion of inner areas of the estuary. Furthermore, $X$. securis exposes a much lower shell area to lift and drag forces in mussel conglomerates. In contrast, the indigenous species M. galloprovincialis secretes thicker byssus threads, which provide stronger in situ attachment displaying a linear increase in strength relative to the size of mussels.

The exposure of both mytilid species to different abiotic factors in the laboratory confirmed the weaker byssus secretion and limited variation in attachment strength in the alien species. On one hand, $X$. securis seemed to be better adapted to life on soft bottoms and not capable of much plasticity when attached to different substrates. However, $X$. securis might be also well adapted to variable environmental conditions, e.g., salinity fluctuations, with no need to modify its byssus properties to ensure secure attachment. Attachment strength of M. galloprovincialis was higher than 


\section{ALR-252v3 - page 2/33}

$X$. securis in all abiotic conditions tested. Results are discussed in relation to the ecological tolerance and impact of these mytilid species.

Keywords: eco-physiology, invasion, attachment strength, bivalves, Xenostrobus securis, Mytilus galloprovincialis

\section{Introduction}

46 A potentially invasive species can enhance its invasive capacity through a number of advantageous physiological characteristics (Sará et al. 2008). For sessile species like mytilids, one such characteristic may be the potential for adhesion to different substrates. Recently, the presence of the alien mytilid $X$. securis (black pygmy mussel) was reported in the inner part of Ría de Vigo

50 (Galicia, NW Spain) by Garci et al. (2007) (Fig. 1). This species is endemic to the brackish waters of New Zealand and Australia and was introduced to Europe (Spain and Italy; Garci et al. 2007;

52 Lazzari and Rinaldi 1994; Sabelli and Speranza 1994) and Japan (Kimura et al. 1999; Kohama et al. 2001). $X$. securis is considered to be a serious threat as a bioinvader with a negative impact on indigenous ecosystems (Darrigran 2002). Today, the indigenous Mytilus galloprovincialis and the alien $X$. securis share the same habitat in Ensenada San Simón (Fig. 1) in the inner part of Ría de

Vigo (NW Spain). M. galloprovincialis settles on hard substrates, whereas $X$. securis is able to live not only on hard rocks but also on muddy and soft bottoms in the inner Ría (Garci et al. 2007). Both these mytilids are filter feeders but in contrast to $M$. galloprovincialis, $X$. securis is usually found on muddy sediments in eutrophic bays and estuaries (Kimura 1994). Hard substrates in the inner Ría de Vigo are not fully occupied by M. galloprovincialis, thus offering space for other species, including $X$. securis, to settle on the granite rocks. Competition for space and food are central issues for ongoing research on the cohabitation of these two species.

Coexistence mechanisms of native and exotic bivalves with similar niches have been reported in several studies based on comparison of ecological traits (Harger 1972; Griffiths and Hockey 1987; Safriel and Sasson-Frostig 1988; Van Erkom Schurink and Griffiths 1990; Zardi et al. 2006, 2007, 2008; Rius and McQuaid 2006; Nicastro et al. 2008, 2010; Dutton and Hofmann 2008; Bownes and McQuaid 2010 among others). Together with its potential to settle on different substrates, like hard rocks and soft and muddy bottoms (personal field observations), X. securis also shows high tolerance to variations in salinity between 5 and 37 psu (Wilson 1968; Kimura et al. 1995). Physical 


\section{ALR-252v3 - page 3/33}

coexistence of competing species (Connell 1961; Dayton 1971; Suchanek 1978), and may also influence the success of biological invasions (Bownes and McQuaid 2010).

According to Garci et al. (2007), more research is needed to understand dynamics of $X$. securis in Galician waters. In addition, the edible mussel M. galloprovincialis, cultivated in the outer areas of Ría de Vigo, has a great economic importance in the region (Labarta et al. 2004). Mussel cultivation in the Rías Baixas (Galicia, NW Spain) represents a total production of about 250000 tons of mussels per year, which is about $40 \%$ of the total European output and $15 \%$ of world mussel production (Labarta et al. 2004). If $X$. securis were to colonise outer areas of the Rías, larvae of this species might settle on ropes where $M$. galloprovincialis is being cultivated, resulting in high economic losses for the mussel industry.

The dynamics of invasion and coexistence between species depend on environmental heterogeneity and its interaction with animal biological responses. Important abiotic factors for population dynamics in the littoral zone include temperature, salinity and water flow/turbulence, as well as the sedimentary effect of the natural substrate and transport of mud or sand (Zardi et al. 2008).

Furthermore, the attachment capacity of a mytilid species is an important factor determining their potential to live in different habitats. Mussels secrete numerous byssus filaments through the foot (Yonge 1962; Price 1983), with each thread connecting proximally to a common stem rooted within the byssus gland of the foot and ultimately to the byssus retractor muscles (Brown 1952; Price 1983; Waite et al. 2002). The distal section of the byssus threads, together with the adhesive plaque establishes the anchorage point (Brown 1952; Waite et al. 2002). Byssogenesis of different species of the Mytilus genus was found to vary according to many abiotic factors, such as temperature

92 (Allen et al., 1976), salinity and water velocity (Van Winkle 1970), agitation or vigorous shaking (Young 1985), oxygen tension (Widdows and Bayne 1971), wave action associated with wind (Price 1982), and circadian and tidal rhythms (Martella 1974). The potential to secrete byssus threads is considered the main source of variability in the force necessary to dislodge mussels in nature, together with other parameters like byssus diameter and the strength of the thread material (Bell and Gosline 1996).

A number of studies have explored the attachment strength of mussels on artificial substrates (Waite 2002; Walter and Liebezeit 2003; Lekang et al. 2003; Filgueira et al. 2007; Burkett et al. 2009; Brenner and Buck 2010). In general, attachment strength can be seen to be influenced by the composition of the substrate material, surface area available, exposure to stress and type of spat collector. Specifically, Brenner and Buck tested a number of spat collector types for the analysis of the attachment properties of the blue mussel Mytilus edulis and observed that nylon (nylonpolyethylene and nylon-polypropylene) and natural fibres offered a better surface for the adhesion 
of mussel spat than other materials such as polyester. Another interesting aspect is that mussels prefer high-energy surfaces (Yamamoto 1995; Waite 2002; Burkett et al. 2009). High-energy substrates like aluminium and glass (Burkett et al. 2009) or polar surfaces like glass and slate

108 (Waite 2002) may help the individuals to maximise adhesion-enhancing adhesive bonding between the mussel plaques and surfaces. In contrast, surfaces like acrylic, PVC and T-2 (Burkett et al. 2009), or Teflon, paraffin and acetal (Waite 2002) represent low energy surface values that minimize an animal's ability to establish adhesion. Nevertheless, the trend correlating surface

112 energy and adhesion is not perfect and variations could have resulted from differences in surface chemistry and moduli changes (Burkett et al. 2009).

114 An alien species may displace indigenous species due to superior competitive abilities and physiological tolerances (Holway 1999; Byers 2000; Steffani and Branch 2005), but interactions

116 with the environment and native species make the invasiveness of an alien unpredictable, and competitive ability can be equalled by the resistance of a community to invasions (Paini et al. 118 2008).

In this study, we aimed to evaluate several eco-physiological responses (byssus attachment strength,

120 morphometry, structure and filament number) of the mytilid $X$. securis under field and laboratory conditions, where mussels were subjected to natural and controlled variation in a number of 122 different abiotic parameters (salinity, flow speed and substrate). The performance of this alien species was compared with the native mytilid $M$. galloprovincialis to explore the degree of

124 adaptation of the alien when facing more saline and turbulent waters than those found in its native environment. We determined the attachment strength and associated byssus apparatus to evaluate 126 the potential of $X$. securis to colonise the rougher and full marine environments in the outer Ría de Vigo where mussel raft culture of the indigenous species M.galloprovincialis is carried out.

\section{Materials and Methods}

\subsection{Field experiment}

132 Field experiments were conducted at two coastal sites in the inner Ría de Vigo (NW Spain), selected according to their environmental conditions. Both sampling sites were located near the city

134 of Vigo (Fig. 1): one in the inner estuary (San Simón: SS) and the other at the mouth of the river Verdugo (Sampaio: SP). Field data was collected during February 2010. In San Simón, both the

136 indigenous mussel M. galloprovincialis and the alien $X$. securis are present in the intertidal zone. In Sampaio (SP) there is only $X$. securis. In situ dislodgement force was assessed for both mytilid species relative to the size range encountered in the field. 


\subsubsection{Abiotic parameters}

Temperature and salinity at the sampling sites were measured using a multi-parameter sensor (XS PC300, Eutech Inst.). Flow speed was measured in situ using a 2D-ACM flow meter (Falmouth Scientific, Inc. Cataumet, MA 02534 USA).

\subsubsection{Attachment strength}

Attachment strengths of eighty mussels, covering the mussel size range encountered in the field (20 - $60 \mathrm{~mm}$ and 15 - $45 \mathrm{~mm}$ shell length for M. galloprovincialis and X. securis, respectively), were measured by connecting the individuals to a spring scale (Kern $\mathrm{MH}$, resolution of $0.01 \mathrm{~N}$ ) with a thin monofilament fishing line through a 2-mm diameter hole drilled through the shell valves close to the posterior margin. Only animals directly attached to the hard substrate were considered. The spring scale was pulled perpendicular ( $90^{\circ}$ pull angle) to the substrate until dislodgement occurred (Bell and Gosline 1997; Babarro and Fernández Reiriz 2010). After dislodgment, a number of 5 15 individuals (depending on the size class, see below) were measured to the nearest millimetre along the antero-posterior (shell length, L), dorso-ventral (shell height, $\mathrm{H}$ ) and lateral axes (shell width, W) using vernier callipers. The shell surface area of the sampled mussels was measured by image analysis (IA), with shell height and width as the main axes defining the area over which the lift force acts (Bell and Gosline 1996). IA measurements were performed using the software QWin

(C) Leica Imaging Systems) on a computer (PC AMD Athlon XP 3000+) connected to a video camera (Leica IC A) on a stereo microscope (Leica MZ6). Camera and light settings were established at the beginning of the analysis and kept constant throughout.

\subsubsection{Byssus secretion in situ: thickness}

The thickness (diameter) of the byssus threads secreted per size class of the mussels was measured using computer-assisted Image Analysis (IA). IA was performed using 15 byssus threads per mussel size class. Considering the mussel size range encountered in situ for attachment strength measurements (see section 2.1.2), we sampled fresh individuals (different ones from those used for the attachment measurements) to obtain the entire byssus and tried to cover a significant range of mussel size. These individuals were grouped within the following size classes: 20, 30, 40, 50 and 60 $\pm 2 \mathrm{~mm}$ (M. galloprovincialis) and $22 \mathrm{~mm}, 27,31,34$, and $38 \pm 2 \mathrm{~mm}$ (X. securis). Proximal and distal portions of the filaments were subdivided into sections along the thread in order to obtain an integrated thickness measurement and were easily distinguishable in the stereo microscope. For the 


\section{ALR-252v3 - page 6/33}

software used and camera conditions, please refer to section 2.1 .2 (shell surface area measurements).

\subsection{Laboratory experiments}

\subsubsection{Maintenance of animals}

Individuals of M. galloprovincialis and X. securis were collected from San Simón (SS) in the inner area of Ría de Vigo (Fig. 1) and transported to the laboratory (within 30 min approx.). Collection was made carefully by scraping the rocks to avoid damaging the byssus gland or byssus stem. Only mussels of $33 \pm 2.0 \mathrm{~mm}$ shell length were collected for the laboratory experiment, as these represented the most frequent size class in the field. Mussels were acclimated for a week in a flowthrough device (Babarro and Fernández Reiriz 2010), using seawater with the following characteristics: $10 \mu \mathrm{m}$-filtered seawater, salinity $35 \mathrm{ppt}$ and temperature $15{ }^{\circ} \mathrm{C}$, at a calm flow speed of $0.1 \mathrm{~cm} \mathrm{~s}^{-1}$. Daily pulses of phytoplankton (Tahitian Isochrysis aff. galbana, T-ISO) mixed with sediment were added to feed the animals (approx. $1.0 \mathrm{mg} \mathrm{L}^{-1}$ ), simulating mean values of food availability in the natural environment of Galician Rías (Babarro et al. 2000). At the end of the acclimatisation, byssus threads secreted by the individuals were removed carefully with a razor blade.

\subsubsection{Factors tested}

Attachment strength of the two mytilid species was investigated and compared according to the following factors: (1) species, M. galloprovincialis or X. securis, (2) flow speed, 5 or $25 \mathrm{~cm} \mathrm{~s}^{-1}$, and (3) substrate, rectangular slates $(28 \times 18 \mathrm{~cm}$, length $\times$ width $)$ or nylon ropes $(2 \mathrm{~cm}$ diameter $)$.

A set of two slates simulating the "mussel bed set up" (one slate per species) was placed on the bottom of a flume tank (see section 2.2.4) with twenty individuals on each slate. Initially, the slates with the mussels were placed in the maintenance tank (flow $=0.1 \mathrm{~cm} \mathrm{~s}^{-1}$ ) for $24 \mathrm{~h}$ to allow individuals can attach to the substrate. Moreover, before the mussels were transferred to the flume tank, they were fixed to the slate plate using a nylon mesh $(1 \mathrm{~cm}$ pore size) to prevent them from falling off if water circulation pressure was excessive. The nylon mesh was removed after $24 \mathrm{~h}$ and as long as no dislodgements of individuals were observed with the experimental flow speed selected in the flume tank, the experiment was started. Animals were exposed to the chosen flow speeds for one week and attachment strength of the individuals to the slates was then measured as reported above (see 2.1.2).

Simultaneously, a second substrate, "rope set up” was also run in the flume tank. Six ropes were installed along the width of the flume tank, all facing the tested flow. Each rope was suspended 


\section{ALR-252v3 - page 7/33}

206 from a grid at the top of the flume tank, and maintained vertically using weights at the bottoms of the ropes. The simultaneous testing of both substrates (slates and nylon ropes) receiving seawater at different depths in the water column of the flume tank (40 cm, see below) did not influence the experimental flow speed. Flow speed values were measured at different depths of the water column in the vicinity of the mussels by using a 2D-ACM flow meter (Falmouth Scientific, Inc. Cataumet, MA 02534 USA). Twenty animals per rope and three ropes per species were socked, allowing the

212 animals to form conglomerates in a multilayer disposition. Initially, we used an elastic cotton net to keep animals attached to the ropes. This net progressively degraded and was completely cut off as

214 soon as the animals attached themselves to the substrate. Once the cotton mesh was completely removed and mussels did not become dislodged from the ropes, the experiment was started.

216 Attachment strength of the mussels to the nylon ropes was measured after one week of exposure to each flow speed (see 2.1.2). Two sets of individuals from the maintenance tanks were used for the 218 two experimental flow speeds tested in the flume tank.

220 Next, a separate experiment was done to estimate the byssus production per individual for each species. A new set of slates with vertical posts was set up (Fig. 2 for detail) and new individuals of both species were transferred from the maintenance tanks to the flume tank. Two slates (one per species) were placed on the bottom of the flume tank with twelve mussels of each species

224 individually glued to vertical posts using “5 minute” epoxy (Imedio S.A. Madrid, Spain). Individuals were suspended $6 \mathrm{~mm}$ above the substrate with their posterior ends facing upstream

226 (Fig. 2), separated by a sufficient distance (one shell length) to avoid any overlap of the byssus threads secreted. For this experiment, we followed the scheme described by Carrington et al. (2008)

228 for an optimal counting of the byssus threads in different bivalve species. The number of byssus threads secreted per individual after one week of exposure to each flow speed was counted and used 230 for the morphometric analysis.

\subsubsection{Substrates}

Slate and nylon ropes were selected as substrates to simulate natural (mostly monolayer on the 234 granitic rocks) and culture (multilayer on culture ropes) dispositions in the laboratory. For this, slate and nylon ropes were chosen as appropriate substrates for mussel attachment processes (see 236 Introduction). Slate represents a high-energy surface (Waite 2002) and a good substrate for mussel attachment after minimal exploration of the surface (Young 1985). Moreover, secreted byssus is 238 easy to collect from this relatively smooth surface by scraping off the adhesive plaques. In contrast, traditional nylon ropes commonly used for mussel aquaculture purposes (Filgueira et al. 2007) were 


\section{ALR-252v3 - page 8/33}

240 selected as a substrate for the animals in the water column of the flume tank. Nylon also represents a good surface for adhesive purposes of the mussels compared with other materials (Brenner and Buck 2010; see Introduction).

\subsubsection{Flow speed}

A circulating flume tank was used to expose mussels to a constant water velocity. The working section of the flume tank corresponded to a water column of $80 \mathrm{~cm}$ length $\times 60 \mathrm{~cm}$ width $\times 40 \mathrm{~cm}$ height. The seawater flowed through a system of collimators (PVC pipes of $2 \mathrm{~cm}$ diameter $\times 100$ cm length) to avoid an excess of turbulence before entering the working section containing the mussels. The flow in the chamber was generated by an axial flow pump and operated at different hertz values, which were converted to flow measurements $\left(\mathrm{cm} \mathrm{s}^{-1}\right)$ using a 2D-ACM flow meter (see section 2.1.1). Considering the fluid dynamic conditions and shape of the flume tank, the flow generated was turbulent even at relatively low velocities (3-5 $\mathrm{cm} \mathrm{s}^{-1}$ ) according to Reynolds number (> 10 000) (Vogel 1994; Ackerman 1999). Velocity measurements in the vicinity of the experimental mussels (ropes in the water column and slates on the bottom of the flume tank) were measured during the experiment to record the actual current flow.

The experiments in the flume tank were started when the animals were attached to the substrates and their valves were clearly open. The temperature of the seawater in the flume tank remained constant at $15 \pm 0.5{ }^{\circ} \mathrm{C}$ and individuals were fed following the conditions described in the section 2.2.1. The water of the flume tank was replaced every three days to remove faeces and other mussel excretions. The experimental flow speeds tested here were chosen to represent calmer and rougher regimes representative of hydrodynamics in the Ría de Vigo, including the influence of the cyclic semidiurnal tides on the water flow speed of the Ría and values obtained for the raft culture disposition (Míguez et al. 2001; Petersen et al. 2008).

\subsubsection{Byssus secretion in the laboratory: quantitative values, thickness, length and surface} texture

The number of byssus threads secreted by a single individual and thickness and length values of the

268 filaments were recorded at the end of each flow trial. The number of byssus threads could only be estimated for M. galloprovincialis. X. securis showed a massive secretion of byssus threads, which made the counting imprecise. When viewed in detail, each single filament of $X$. securis is composed of multiple threads with diminutive adhesive plaques (Fig. 2). Threads secreted by $M$.

272 galloprovincialis were easily counted using a binocular dissection microscope (Nikon SMZ-10 at 4fold magnification). For complete byssus collection, filaments were carefully cut from the proximal 


\section{ALR-252v3 - page 9/33}

274 section, close to the stem, and the plaque was scraped off at the end of the distal part attached to the slate. Only new threads secreted during the experiment and attached to the slate were considered.

276 The remaining old threads secreted before the experiment were easily recognizable by their equal and shorter size, dark brown colour (Bell and Gosline 1996) and lack of plaque at the end of the 278 distal part.

For thickness measurements of the byssus secreted in the laboratory, see section 2.1.3. 280 Approximately hundred threads from 10 mussels (10 threads per mussel) were analysed for each mytilid species. The length of the entire byssus and its proximal and distal portions were also 282 measured for both species by Image analysis (IA).

Scanning electron microscopy (SEM) was used to examine the surface texture of the proximal and distal sections of the byssus secreted by the two species.

\subsection{Statistical analysis}

In situ attachment strength of the mussels in relation to individual size was fitted to linear functions.

288 Projected shell area of mussels as a function of individual size was fitted to potential allometric equations $\left(Y=a \cdot X^{b}\right)$. Three-way ANOVA was used to estimate the influence of species, flow speed and substrate on attachment strength variability (logarithmic transformed data) of the $33 \mathrm{~mm}$ (shell length) mussels selected for the laboratory experiment. One-way ANOVA was used to test the effect of flow speed on the amount of byssus threads secreted by $M$. galloprovincialis and the percentage of the thread length that each section of the byssus (proximal and distal) represented. The effect of species and flow speed on the proximal and distal thickness values of the byssus threads was tested by two-way ANOVA. Independence of cases was assumed and normality checked with the Shapiro-Wilk test. Homoscedasticity between experimental groups of mussels was established using Levene's test. When data did not fit normality tests or variances were not homogenous, the non-parametric Kolmogorov-Smirnov test was used. All analyses performed with STATISTICA 6.0 except the normality test, for which R software version 2.10.1 was used.

\section{Results}

\subsection{Field experiment}

\subsubsection{Abiotic parameters}

Flow speed, temperature and salinity data collected during sampling of mussels at the field stations are presented in Table 1. Flow speed varied widely at Sampaio (SP) depending on the tidal regime and the impact of freshwater flow, with values ranging between 8.0 and $123.1 \mathrm{~cm} \mathrm{~s}^{-1}$. Similarly, 


\section{ALR-252v3 - page 10/33}

308 salinity fluctuated abruptly at the Sampaio site (SP) within the range of $6.2-32.0 \mathrm{ppt}$, including low and high tide cycles. Temperature values of seawater during sampling of individuals at 310 Sampaio (SP) varied between 9.8 and $10.8^{\circ} \mathrm{C}$.

Mean values of flow speed in the inner Ría de Vigo site (San Simón, SS) varied over the range 0 -

$3122.3 \mathrm{~cm} \mathrm{~s}^{-1}$. Temperature and salinity values fluctuated over the range $11.3--13.2{ }^{\circ} \mathrm{C}$ and $32.0-$ 32.4 ppt, respectively, during the period of mytilid sampling, which included both low and high 314 tides.

\subsubsection{Attachment strength and animal's shape}

The shapes of the two mytilid species are illustrated in Fig. 3a. According to the size range 318 observed in the field (Fig. 3b), the black pygmy mussel $X$. securis is a mytilid usually smaller than $40 \mathrm{~mm}$ shell length. For a given shell length (Fig. 3a), the main difference between the two species

320 corresponded to the shell height value, which was significantly higher for indigenous $M$. galloprovincialis. This morphological difference between the two species means that the shell area

322 exposed to lifting forces in a mussel bed is also higher for $M$. galloprovincialis over the whole of its size distribution (Fig. 3b). There was a significant increase in attachment strength of $M$.

324 galloprovincialis with mussel size, from values of $8 \mathrm{~N}$ (individuals of $20 \mathrm{~mm}$ shell length) to $31 \mathrm{~N}$ (individuals of $60 \mathrm{~mm}$ shell length) (Fig. 4a). The relationship between attachment strength and mussel size was not significant in the alien $X$. securis, regardless of experimental site. Attachment strength values of the alien $X$. securis varied between 6 and $12 \mathrm{~N}$ for the whole mussel size range 328 (Fig. 4b).

During dislodgement measurements, the way the byssus broke was observed in both mytilid 330 species. Filaments of M. galloprovincialis occasionally broke at the thread level (proximal section), although both substrate and adhesive plaque were very common failure points. In contrast, byssus of $X$. securis frayed inconsistently along the thread like chewing gum.

\subsubsection{Byssus thickness}

Thickness of the byssus secreted by the mytilids followed a similar pattern to that of mussel 336 attachment strength (Fig. 4c-d). Linear increase in the attachment strength of $M$. galloprovincialis with increasing size was correlated with linear increase of thread diameter in both proximal and distal sections (Fig. 4c). Byssus thickness in threads secreted by $M$. galloprovincialis varied between $92 \mu \mathrm{m}$ (proximal) and $52 \mu \mathrm{m}$ (distal), for the smallest mussel size class of $20 \mathrm{~mm}$ shell

340 length, and $134 \mu \mathrm{m}$ (proximal) and $120 \mu \mathrm{m}$ (distal) for the $60 \mathrm{~mm}$ (largest) mussel size class (Fig. 4c). 


\section{ALR-252v3 - page 11/33}

342 As with the attachment strength variability, proximal and distal thickness of the byssus threads of the black pygmy mussel $X$. securis did not follow any significant pattern with increasing size (Fig.

344 4b). Thickness of byssus varied over the range of $26-41 \mu \mathrm{m}$ in the proximal section and $13-19$ $\mu \mathrm{m}$ in the distal section for the mussel size range analysed (Fig. 4d).

\subsection{Laboratory experiment}

\subsubsection{Attachment strength as a function of species, flow speed and substrate}

Three-way ANOVA on the attachment strength variability of the mussels showed that all factors tested (species, flow and substrate) caused highly significant effects. The strongest effect was species $(p<0.001)$. Indeed, attachment strengths of $M$. galloprovincialis were two (slate) or three (ropes) times higher than those of $X$. securis ( $<$ 0.001) (Fig. 5a-b). Otherwise, there was a positive effect of increasing flow speed on attachment strength of the mussels $(p<0.01)$, although this effect was dependent on the substrate and occurred only when the animals were on slates (Fig. 5a). Both mytilids increased attachment strength by approximately two-fold on slates when facing a flow of $25 \mathrm{~cm} \mathrm{~s}^{-1}$ compared with one of $5 \mathrm{~cm} \mathrm{~s}^{-1}$ (Fig. 5a). No effect of flow speed on attachment strength of either mytilid was recorded when animals were attached to nylon ropes, values ranging from $3.5 \mathrm{~N}$ for $X$. securis to $9.5 \mathrm{~N}$ for $M$. galloprovincialis regardless of flow speed (Fig. 5b). In the substrate comparison, a significant effect was found on the attachment strength of mussels $(p<0.001)$ but this was dependent on species. Interestingly, M. galloprovincialis attached more strongly to nylon ropes (up to $9.5 \mathrm{~N} ; p<0.0001$ ) than to slates (4-7 $\mathrm{N}$ for both experimental flows) (Fig. 5a-b).

Attachment strength of $X$. securis individuals was not significantly different between slates and nylon ropes, with values ranging between $2.7-4.3 \mathrm{~N}$ (Fig. 5a-b).

\subsubsection{Byssus secretion: quantitative values, thickness, length and surface texture}

The amount of byssus threads secreted by M. galloprovincialis was significantly higher (40\%) when individuals were exposed to higher flow speed (Fig. 6). Such increase in byssus secretion might also be correlated with the higher attachment strength observed for M. galloprovincialis exposed to higher flow speed on slates (Fig. 5a). No recordings were made of the number of filaments secreted by $X$. securis (see Materials and Methods). With regard to byssus thickness values, filaments secreted by $X$. securis were 3-5 times thinner than byssus secreted by $M$. galloprovincialis depending on the byssus section (Table 2). Thickness of the distal section of the byssus only differed according to species, with mean values of $70 \mu \mathrm{m}$ and $15 \mu \mathrm{m}$ for $M$. galloprovincialis and $X$. securis, respectively (Table 2). In contrast, both species and flow speed had significant effects on the thickness of proximal byssus (Table 2). Indeed, proximal byssus was much 


\section{ALR-252v3 - page 12/33}

376

thicker for filaments secreted by M. galloprovincialis individuals (Table 2) with values of $100 \mu \mathrm{m}$, although there were no differences with flow speed within this species (Table 2). In contrast, there was a $22 \%$ increase in the thickness of proximal filaments secreted by $X$. securis (from 28 to 35 $\mu \mathrm{m} ; p<0.001$; Table 2) with the tested increase in flow speed. Interestingly, the length of this proximal section of the byssus secreted by $X$. securis was also modified when individuals were faced with higher flow speed. The proximal section of byssus represented $6.9 \%$ of the thread length in $X$. securis at $5 \mathrm{~cm} \mathrm{~s}^{-1}$, and increased up to $11 \%$ of the whole thread at a flow speed of $25 \mathrm{~cm} \mathrm{~s}^{-1}$ ( $p<0.001$; Table 2). Proximal length of the byssus secreted by $M$. galloprovincialis remained unchanged (22 - $24 \%$ ) when subjected to different flow speeds (Table 2).

Length of entire byssus filaments in $X$. securis did not differ between the flow rates tested in the laboratory (mean value of $10.6 \mathrm{~mm}$; Table 2). Similarly to $X$. securis, no differences in thread length were found for M. galloprovincialis exposed to different flow speeds (mean value of 13.2 $\mathrm{mm}$; Table 2). A species comparison of byssus length, however, showed that filaments were significantly longer in $M$. galloprovincialis than in $X$. securis $(p<0.05)$.

Scanning electron microscopy of byssus threads secreted by the two mytilids revealed differences in surface texture of the threads (Fig. 7). Distal sections in both mytilids were generally smooth with no differences between species. Proximal sections, however, were clearly corrugated in both species which highlighted interspecific differences in structure along the thread. More interestingly, proximal section of the byssus in threads secreted by $M$. galloprovincialis showed more crimped and corrugated fibres (Fig. 7). The proximal section of the byssus secreted by $X$. securis showed not only transverse grooves, like M. galloprovincialis, but also longitudinal ones that alternated along the thread forming a completely different structure (Fig. 7).

\section{Discussion}

The alien species $X$. securis is able to colonise a wide variety of substrates from muddy/soft bottoms to hard rocks. $X$. securis can also inhabit very different estuarine bottoms with broadly differing granulometry values in terms of proportions of gravel, sand and mud in the inner areas of Ría de Vigo (Pascual et al. 2010). Moreover, X. securis has also been reported as a wide tolerant species with regard to environmental salinity, between 5 and 37 ppt (Kimura et al. 1995), which corresponds to the environmental range in our studied area. Our field observations showed that both species live together on natural hard substrates on the inner coastline of Ría de Vigo (San Simón SS). However, the indigenous mussel M. galloprovincialis is practically absent from soft 


\section{ALR-252v3 - page 13/33}

410 bottoms in the inner Ría de Vigo Sam Simón (SS) and Sampaio sites (SP) where $X$. securis grows at high density (Garci et al. 2007).

412 Xenostrobus securis attached to natural rocks in the field with similar strength regardless of the environment, even though the abiotic parameters differed sharply. At first view, $X$. securis might 414 appear to have a broad ecologically tolerance here, establishing a rather constant attachment strength regardless of habitat and mussel size. However, our laboratory experiments demonstrated a certain ability of the alien species to modify attachment strength through its byssus properties when subjected to differences in flow speed, though at a significantly lower magnitude $\left(5-25 \mathrm{~cm} \mathrm{~s}^{-1}\right)$ than reported at the field station in SP where the conditions were roughest (up to $123 \mathrm{~cm} \mathrm{~s}^{-1}$ ). Thus, attachment strength of the alien species might be a more dynamic eco-physiological parameter than expected from the field data.

Attachment strength of $X$. securis to hard rocks was significantly lower than M. galloprovincialis for most of the size range. Despite the lower attachment strength in the field, $X$. securis survived both in the relatively calm and brackish waters of San Simón and in the most exposed site at Sampaio (mouth of the River Verdugo), where flow speeds are greater. It is well known that the forces exerted on organisms in clusters are smaller than the forces the same individuals would experience if alone (Johnson 2001; Vogel 1984), which means that forces will decrease with increasing cluster density (Carrington et al. 2008; Brenner and Buck 2010). This could be one of the reasons why individuals are able to grow and form dense conglomerates in the highly exposed mouth of the River Verdugo (Sampaio SP). On the other hand, the alien $X$. securis might be able to colonise the inner areas of the Ría de Vigo at lower density values because of its great tolerance to salinity fluctuation in the estuary, combined with its byssus characteristics.

In San Simón, $X$. securis colonised hard substrates not fully occupied by the indigenous mussel $M$. 434 galloprovincialis. Clearly, the higher attachment strength of $M$. galloprovincialis would be a dominant characteristic for this species in terms of space competition, i.e., for natural rocks. Differences in thickness of byssus secreted by the two mytilids might help to explain this. A single thread of $M$. galloprovincialis was much thicker in both proximal (3×) and distal (5×) parts of the 438 filaments than a thread secreted by $X$. securis, and a thicker filament would be able to sustain a higher tension load. The extremely thin byssus secreted by $X$. securis was counterbalanced by its production of a huge amount of byssus threads. This might be considered as an important speciesspecific feature that could help this alien mytilid to become an invader. To our knowledge, only $X$. securis (present study) and the dreissenid mussel Mytilopsis sallei (the black striped mussel from 


\section{ALR-252v3 - page 14/33}

Indian tropical waters; Udhayakumar and Karande 1989) present such an extraordinary capacity to 444 produce up to 1000 filaments per byssus gland.

Apart from the amount of byssus, $X$. securis secreted the thinnest byssus threads recorded for any of the Mytilidae and even some species of the family Dreissenidae (see Brazee and Carrington 2006 and Kennedy 2011 for the exact name of the species), although such comparisons may be influenced by mussel size if this has a relationship with byssus morphometry as seen in our study. Moreover, the area of the plaques attached to the substrate was also 9 times larger in $M$. galloprovincialis $\left(0.81 \mathrm{~mm}^{2}\right)$ than in $X$. securis $\left(0.09 \mathrm{~mm}^{2}\right)$ (preliminary observations). X. securis has, together with Modiolus modiolus, the smallest plaque size of several, previously studied, bivalve molluscs (Udhayakumar and Karande 1989; Brazee and Carrington 2006). Threads and plaques are moulded by the mussel foot, which may vary in size (Brazee and Carrington 2006). For a given size of animal, the foot organ of the black pygmy mussel $X$. securis is much smaller than that of M. galloprovincialis (Fig. 8) and although this also represents a species characteristic, it might be also correlated with secretion of the much thinner byssus and smaller adhesive plaques.

458 As a consequence of the tidal cycle movements of seawater, and assuming that larvae of both species appear in the seawater samples at inner Ría de Vigo (Santaclara et al. 2007), both mytilids would have an equal potential to colonise different substrates on the coastline, i.e., soft bottoms and hard substrates. The fact that the alien species colonises both soft bottoms and hard rocks could indicate a wider range of tolerance that might be correlated with its byssus. Meadows and Shand (1989) observed that semi-infaunal species produce a very large number of thin threads, whereas

464 epifaunal species produce a smaller number of thicker threads. Most likely, by the secretion of great number of thin threads, this alien bivalve would be more effective at inhabiting semi-infaunal conditions, as the threads can create an extensive network of individual attachments to small particles (Pearce and LaBarbera 2009). In contrast, Mytilus species attach themselves to rocks and other hard substrates with a smaller number of thick threads that provide a more reliable tether against wave action or predation (Bell and Gosline, 1996; Bell and Gosline, 1997; Carrington, 470 2002).

Another interesting aspect is related to the byssus surface texture observations in the two mytilids.

472 In a comparison of mytilid species (Brazee and Carrington 2006), the surface texture of the proximal byssus of $X$. securis resembled that of M. modiolus (Fig. 6 in Brazee and Carrington 474 2006). Mytilus galloprovincialis can be grouped together with the blue mussel M. edulis according to the scheme presented by Brazee and Carrington. Both Mytilus species have a corrugated and crimped proximal byssus section, related to large extensibility values typically observed in 


\section{ALR-252v3 - page 15/33}

epibyssate individuals (Bell and Gosline 1996). In contrast, proximal byssus in $X$. securis presented longitudinal and transverse grooves alternating along this byssus section. Hypothetically, a less extensible proximal byssus in $X$. securis would reflect a similar ecological transitional mode to that reported for $M$. modiolus, adapted to living commonly on muddy/soft bottoms but also on hard substrates (Stanley 1972; Holt et al. 1998; present study) through changes in the byssus properties (number of threads, morphometry and, most likely, mechanical properties).

As previously mentioned, $X$. securis may live across a wide salinity range (Kimura et al. 1995) and is more tolerant to this abiotic factor than M. galloprovincialis (Braby and Somero 2006). Consequently, salinity variation could also play a key role regulating the field distribution of both mytilids, though wide differences in environmental salinity did not affect attachment strength of the alien mussel. For Mytilus sp., salinity represents a more significant factor than temperature in regulating species distribution of $M$. galloprovincialis, M. trossulus and M. edulis (Braby and 490 Somero 2006). In our survey, such lower tolerance to salinity variation in M. galloprovincialis was obvious, since this mytilid was not present near the mouth of river Verdugo (Sampaio SP) where 492 the alien $X$. securis is the highly dominant species. The precise contribution of these two factors (species-specific byssus properties and salinity adaptation patterns) in explaining the distribution and survival of the alien species cannot be properly differentiated using our experimental design.

496 The laboratory experiment demonstrated that $M$. galloprovincialis had the strongest attachment under the abiotic conditions tested (different flow speeds and substrates). It was noted that 498 attachment strength of both mytilids was significantly lower in the laboratory than in the field experiment for a given mussel size, i.e., $33 \mathrm{~mm}$ shell length. These differences could be due to the 500 relatively shorter and longer periods of exposure that individuals had to the natural (field, life cycle) and artificial substrates (lab, 1-2 weeks), respectively, and the heterogeneity of the natural 502 environment compared with the fixed abiotic environment selected for the laboratory experiment. Moreover, different types of aggregation established by the mussels in field and laboratory 504 conditions (cluster density, byssus network, multilayer disposition, etc), and other biotic factors like predation pressure might have contributed to these differences. Again, differences in attachment 506 strength between species might be partially accounted for by the secretion of thicker and longer byssus threads in M. galloprovincialis. Nevertheless, several aspects can be remarked in the species 508 comparison. Animals may adjust their dislodgement force by varying the number of byssus threads, their thickness and the byssus material strength (Bell and Gosline 1997, Carrington 2002). In our 510 survey, despite the lack of byssus thread number data for the alien $X$. securis, we observed that 


\section{ALR-252v3 - page 16/33}

these two mytilids followed different strategies to increase attachment strength when necessary. $M$. galloprovincialis attached to slates secreted a higher number of filaments (40 \%) when exposed to a higher flow speed, though byssus thickness remained unchanged. In contrast, $X$. securis attached to 514 slates secreted proximally thicker and longer byssus when exposed to higher flow speed, which might be correlated with the observed increase in attachment strength. This morphometric plasticity of the proximal byssus in $X$. securis, together with the resemblance of its surface texture to another transitional species, $M$. modiolus (see above), and its extraordinary potential to secrete byssus

518 filaments combine to make $X$. securis a species with an extremely wide tolerance to abiotic changes, i.e., flow speed and substrates, which in turn might be the basis for its great invasive 520 potential.

522 Attachment strength of M. galloprovincialis on nylon ropes was twice that of the same species on slates at a flow speed of $5 \mathrm{~cm} \mathrm{~s}^{-1}$, but such a difference in attachment strength between substrates was not observed for $X$. securis, leading to even greater differences between the species when they were put on ropes. Interestingly, flow speed increase did not cause any change in the attachment 526 strength of either mytilid when they were attached to nylon ropes. As was noted above, hydrodynamic forces that individuals face in conglomerates decrease with the increasing cluster density (Carrington et al. 2008; Brenner and Buck 2010) as a consequence of the neighbourhood protection against the impact of the current (Buck and Buchholz 2005). This protective effect of mussel clumps needs to be quantified more precisely in future surveys, but it is plausible to hypothesise that M. galloprovincialis might have experienced higher load values when attached in a

532 vertical position on ropes, due to its higher shell surface (and weight) exposed to the flow. In contrast, $X$. securis might be more "hydrodynamic" in terms of body shape to be firmly attached on 534 ropes, with a hypothetically lower weight factor, and this may have helped it to establish more compact and uniform clusters on the ropes in the flume tank (personal observations). This

536 hypothesis needs to be confirmed with new research considering drag and lift reduction analysis, using individuals of both species forming conglomerates.

The alien species demonstrated great adaptability to different ecosystems by growing in 540 heterogeneous environments with a wide fluctuation in salinity, flow speed and substrate type. The ecological tolerance reported here, together with its growth rates and density of individuals in inner 542 Ría de Vigo (Garci et al. 2007) imply that it could threaten the indigenous mussel $M$. galloprovincialis cultivated in Galicia Rías. Cultivation of M. galloprovincialis takes place mainly 544 in the outer areas of the Ría de Vigo. However, as was shown in the present survey, $X$. securis is 


\section{ALR-252v3 - page 17/33}

\section{6}

able to attach and perform in rougher and full marine environments. M. galloprovincialis is an important cultivated marine resource in Galician (NW Spain) providing jobs for 11500 people and generating 420 millions euros annually (Santaclara et al. 2007). More than 3000 rafts are used to cultivate this indigenous mussel along the coastline, with an extraordinary socio-economic impact in the area (see Introduction). Moreover, the alien $X$. securis could affect other species by altering marine and brackish water ecosystems at different levels.

In summary, in situ attachment strength of M. galloprovincialis was significantly higher than that of $X$. securis, and a laboratory experiment confirmed this pattern on both slate and rope substrates. Byssus thickness secreted by each of these mytilid species might represent the basis of these attachment strength differences. Secretion of an extremely thin but vast number of byssus filaments by the alien $X$. securis is extraordinary (not previously recorded in other Mytilidae) and highlights a great advantage that, coupled with its capacity to inhabit heterogeneous environments, could allow this species to become invasive. Surprisingly, $X$. securis showed a certain plasticity enabling it to modify morphological characteristics of the (proximal) byssus to potentially increase attachment strength on hard substrates under rougher conditions. Moreover, analysis of the surface texture of the byssus suggested that $X$. securis can be grouped together with the well-known transitional species $M$. modiolus (from partially buried to epibyssate). These byssus features, together with the species-specific euryhaline response of the alien mytilid, could mean it represents a threat for the ecosystem of the Ría de Vigo as a whole.

Nevertheless, the overall results presented here can be interpreted in two different but compatible ways. First, the alien species secreted weaker byssus and presented a limited ability to modify byssus characteristics and attachment strength on nylon ropes. This would make $X$. securis better adapted to inhabit soft bottoms (with a profuse network established with its abundant byssus threads) and less capable of much plasticity on other substrates. At the same time, $X$. securis might also be well adapted to a multitude of environments (i.e., wide salinity fluctuation) by establishing a secure attachment with no need to modify byssus secretion properties. Attachment strength of $M$. galloprovincialis was higher than $X$. securis in all abiotic conditions tested. Consequently, this indigenous species would not suffer extreme competition by the alien on natural rocks unless salinity values were to vary abruptly. In the latter case, $X$ securis would be the better performer. Further research is necessary to understand adult competition patterns for food and space as well as larval dispersal and recruitment patterns in the inner and outer Ría. Such investigation would confirm the true potential of this alien species to hypothetically colonise areas where raft mussel culture is carried out. 
Acknowledgements. We would like to thank E. Silva Caride for technical assistance in the field and laboratory. We also thank Jesús Méndez (CACTI, University of Vigo) for SEM analysis of the bysuss texture. This study was funded by the project AGL2010-16464 Dirección General de Investigación y Gestión del Plan Nacional de I+D+i (Ministerio de Ciencia e Innovación 2011-2013, Spanish Government).

\section{References}

588 Ackerman J.D., 1999, Effect of velocity on the filter feeding of dreissenid mussels (Dreissena polymorpha and Dreissena bugensis): implications for trophic dynamics. Can. J. Fish. Aquat. Sci. 56, 1551-1561.

590 Allen J.A., Cook M., Jackson D.J., Preston S., Worth E.M., 1976, Observations on the rate of production and mechanical properties of the byssus threads of Mytilus edulis L. J. Mollus. Stud. 42, 279-289.

592 Babarro J.M.F., Fernández-Reiriz M.J., Labarta U., 2000, Feeding behaviour of seed mussel Mytilus galloprovincialis: environmental parameters and seed origin. J. Shellfish Res. 145 (2), 204-213.

594 Babarro J.M.F., Fernández-Reiriz M.J., 2010, Secretion of byssal threads in Mytilus galloprovincialis after spawning stress. J. Comp. Physiol. B 180, 95-104.

596 Bell E.C., Gosline J.M., 1996, Mechanical design of mussel byssus: material yield enhances attachment strength. J. Exp. Biol. 199, 1005-1017.

598 Bell E.C., Gosline J.M., 1997, Strategies for life in flow: tenacity, morphometry, and probability of dislodgement of two Mytilus species. Mar. Ecol. Prog. Ser. 159, 197-208.

600 Bownes S.J., McQuaid D., 2010, Mechanisms of habitat segregation between an invasive (Mytilus galloprovincialis) and an indigenous (Perna perna) mussel: adult growth and mortality. Mar. Biol. 157, 1799-1810.

Brazee S.L., Carrington E., 2006, Interspecific comparison of the mechanical properties of mussel byssus. Biol. Bull. 211, 263-274.

Brenner M., Buck B.H., 2010, Attachment properties of blue mussel (Mytilus edulis L.) byssus threads on culture-based artificial collector substrates. Aquacult. Eng. 42, 128-139.

Braby C.E., Somero G.N., 2006, Following the heart: temperature and salinity effects on heart rate in native and invasive species of blue mussels (genus Mytilus). J. Exp. Biol. 209, 2554-2566.

Brown C.H., 1952, Some structural proteins of Mytilus edulis L. Quart. J. Micros. Sci. 93, 487-502.

612 Burkett J.R., Wojtas, J.L., Cloud, J.L., Wilker, J.J., 2009, A method for measuring the adhesion strength of marine mussels, J. Adhesion, 85 (9), 601-615.

614 Byers J.E., 2000, Differential susceptibility to hypoxia aids estuarine invasion. Mar. Ecol. Prog. Ser. 203, 123-132.

616 Carrington E., 2002, Seasonal variation in the attachment strength of the blue mussel: causes and consequences. Limnol. Oceanogr. 47, 1723-1733.

618 Carrington, E., Moeser G.M., Thompson S.B., Coutts L.C., Craig C.A., 2008, Mussel attachment on rocky shores: the effect of flow on byssus production. Int. Comp. Biol. 48, 801-807.

620 Connell J.H., 1961, The influence of interspecific competition and other factors on the distribution of the barnacle Chthamalus stellatus. Ecology 42, 710-723.

622 Darrigran G, 2002, Potential impact of filter-feeding invaders on temperate inland freshwater environments. Biol. Invasions 4, 145-156.

624 Dayton P.K., 1971, Competition, disturbance and community organization: the provision and subsequent utilization of space in a rocky shore intertidal community. Ecol. Monogr. 41, 351-389.

626 Dutton J.M., Hofmann G.E., 2008, Spatial and temporal variation in distribution and protein ubiquitination for Mytilus congeners in the California hybrid zone. Mar. Biol. 154, 1067-1075.

628 Filgueira R., Peteiro L.G., Labarta U. Fernández-Reiriz M.J., 2007, Assessment of spat collector ropes in Galician mussel farming. Aquacult. Eng. 37, 195-201. 
Garci M.E., Trigo J.E., Pascual S., Gonzalez A.F., Rocha F., Guerra A., 2007, Xenostrobus securis (Lamarck, 1819) (Mollusca: Bivalvia): first report of an introduced species in Galician waters. Aquacult. Int. 15, 19-24.

Griffiths C.L., Hockey P.A.R., 1987, A model describing the interactive roles of predation, competition and tidal elevation in structuring mussel population. S. Afr. J. Marine Sci. 5, 547-556.

Harger J.R., 1972, Competitive co-existence: maintenance of interacting associations of the sea mussel Mytilus edulis and Mytilus californianus. Veliger 14, 387-410.

Holt T.J., Rees E.I., Hawkins S.J., Seed R., 1998, Biogenic Reefs, Vol. 9: An Overview of Dynamic an Sensitivity Characteristics for Conservation Management of Marine SACs. Scottish Association of Marine Sciences/UK Marine SACs Project, Oban, Scothland.

Holway D.A., 1999, Competitive mechanisms underlying the displacement of native ants by the invasive Argentine ant. Ecology 80, 238-251.

Johnson A.S., 2001, Drag, drafting, and mechanical interactions in canopies of the red alga Chondrus crispus. Biol. Bull. Mar. Biol. Lab. 201 (2), 126-135.

Kennedy V.S., 2011, Biology of the uncommon dreissenid bivalve Mytilopsis leucophaeata (Conrand, 1831) in central Chesapeake Bay. J. Mollus. Stud. 77 (2), 154-164.

Kohama T., Montani S., Kajiwara Y., Yamada M., 2001, Population dynamics of sessile bivalves Mytilus galloprovincialis and Xenostrobus securis in hyper eutrophicated bay, Japan. Bull. Jpn Soc. Fish Sci. 67, 664-671.

Kimura T., 1994, The population dynamics of Musculista senhousia (Benson) and Limnoperna fortunei kikuchii Habe in Lake Hamana, especially the ecological study of larval recruitment. PhD thesis, Mie University, Mie, Japan.

Kimura T., Kakuta T., Kurokura H., 1995, Salinity tolerance and osmoregulation in freshwater and brackish water mytilids (Mytilidae: Genus Limnoperna). Bull. Soc. Sea Water Scientist. Jpn. 49,148-152.

Kimura T, Masaaki T., Yasuhiro S., 1999, Limnoperna fortunei kikuchii Habe, 1981 (Bivalvia : Mytilidae) is a synonym of Xenostrobus securis (Lamarck, 1918) : introduction into Japan from Australia and/or New Zealand. Japanese Jpn J. Malacol. 58, 101-117.

Labarta, U., Fernández-Reiriz, M.J., Pérez-Camacho, A., Pérez Corbacho, E., 2004, Bateeiros, mar, mejillón. Una perspectiva bioeconómica. CIEF. Fundación Caixagalicia, Santiago de Compostela, 262 pp., ISBN 84-95491-69-9.

Lazzari G., Rinaldi E., 1994, Alcune considerazione sulla presenza di specie extra Mediterranee nelle lagune salmastre di Ravenna. B. Malacol. 30, 195-202.

Lekang O.-I., Stevik T.K., Borno A.M., 2003, Evaluation of different combined collectors used in longlines for blue mussel farming. Aquacult. Eng. 27, 89-104.

Martella T., 1974, Some factors influencing byssus thread production in Mytilus edulis (Mollusca: Bivalvia) Linnaeus, 1758. Water Air Soil Poll. 3, 171-177.

Meadows P.S., Shand P., 1989, Experimental analysis of byssus thread production by Mytilus edulis and Modiolus modiolus in sediments. Mar. Biol. 101, 219-226.

Míguez B.M., Farina-Busto L., Figueiras F.G., Pérez F.F., 2001, Succession of phytoplankton assemblages in relation to estuarine hydrodynamics in the Ría de Vigo: A box model approach. Sci. Mar. 65 (1), 65-76

Nicastro K.R., Zardi G.I., Mcquaid C.D., 2008, Movement behaviour and mortality in invasive and indigenous mussels: resilience and resistance strategies at different spatial scales. Mar. Ecol. Prog. Ser. 372, 119-126.

Nicastro K.R., Zardi G.I., Mcquaid C.D., 2010, Differential reproductive investment, attachment strength and mortality of invasive and indigenous mussels across heterogeneous environments. Biol. Invasions, 12, 2165-2177.

Paini D.R., Funderburk J.E., Reitz S.R., 2008, Competitive exclusion of a worldwide invasive pest by a native. Quantifying competition between two phytophagous insects on two host plant species. J. Anim. Ecol. 77, 184-190.

Pascual S., Villalba A., Abollo E., Garci M., González A.F., Nombela M., Posada D., Guerra A., 2010, The mussel Xenostrobus securis: a well-established alien invader in the Ria de Vigo (Spain, NE Atlantic). Biol. Invasions 12, 2091-2103.

Pearce T., LaBarbera M., 2009, Biomechanics of byssal threads outside the Mytilidae: Atrina rigida and Ctenoides mitis. J. Exp. Biol. 212, 1449-1454. 
684 Petersen J.K., Nielsen T.G., van Duren L., Maar M., 2008, Depletion of plankton in a raft culture of Mytilus galloprovincialis in Ría de Vigo, NW Spain. I. Phytoplankton. Aquat. Biol. 4, 113-125.

686 Price H.A., 1982, An analysis of factors determining seasonal variation in the byssal attachment strength of Mytilus edulis L. J. Mar. Biol. Ass. U.K. 62, 147-155.

688 Price H.A., 1983, Structure and formation of the byssus complex in Mytilus (Mollusca, Bivalvia). J. Mollus. Stud. 49, 9-17.

690 Rius M., McQuaid C.D., 2006, Wave action and competitive interaction between the invasive mussel Mytilus galloprovincialis and the indigenous Perna perna in South Africa. Mar. Biol. 150 (1), 69-78.

Sabelli B., Speranza S., 1994, Rinvenimento di Xenostrobus sp. (Bivalvia, Mytilidae) nella laguna di Venecia. B. Malacol. 29, 311-318.

694 Safriel U.N., Sasson-Frostig Z., 1988, Can colonizing mussel outcompete indigenous mussel? J. Exp. Mar. Biol. Ecol. 117, 211-226.

696 Santaclara F.J., Espiñeira M., Vieites J.M., 2007, Molecular Detection of Xenostrobus securis and Mytillus galloprovincialis Larvae in Galician Coast (Spain). Mar. Biotechnol. 9, 722-732.

698 Sará G., Romano C., Widdows J., Staff F.J., 2008, Effect of salinity and temperature on feeding physiology and scope for growth of an invasive species (Brachidontes pharaonis - MOLLUSCA: BIVALVIA) within the Mediterranean sea. J. Exp. Mar. Biol. Ecol. 363 (1-2), 130-136.

Stanley S.M., 1972, Functional morphology and evolution of byssally attached bivalve molluscs. J. Paleontol. 46, 165-212.

Steffani C.N., Branch G.M., 2005, Mechanisms and consequences of competition between an alien mussel, Mytilus galloprovincialis, and an indigenous limpet, Scutellastra argenvillei. J. Exp. Mar. Biol. Ecol. 317, 127-142.

706 Suchanek T.H., 1978, The ecology of Mytilus edulis L. in exposed rocky inertial communities. J. Exp. Mar. Biol. Ecol. 31, 105-120.

708 Udhayakumar, M., Karande, A.A., 1989, Byssal threads of Mytilopsis sallei (Recluz) and their adhesive strength. Proc. Indian Acad. Sci. (Anim. Sci.) 98 (1), 65-76.

710 Van Erkom Schurink C., Griffiths C.L., 1990, Marine mussels of Southern Africa-their distribution patterns, standing stocks, exploition and culture. J. Shellfish Res. 9, 75-85.

712 Van Winkle W., 1970, Effect of environmental factors on byssal thread formation. Mar. Biol. (Berlin) 7, 143-148.

714 Vogel S., 1984, Drag and flexibility in sessile organisms. Am. Zool. 24 (1), 37-44.

Vogel S., 1994, Life in moving fluids, $2^{\text {nd }}$ ed. Princeton University Press, Princeton, NJ.

716 Waite J.H., 2002, Adhesion á la moule. Integr. Comp. Biol., 42, 1172-1180.

Waite J.H., Vaccaro E., Sun C., Lucas J.M., 2002, Elastomeric gradients: a hedge against stress concentration in marine holdfasts? Phil. Trans. R. Soc. Lond. B. 357,143-153.

Walter U., Liebezeit G., 2003, Efficiency of blue mussel (Mytilus edulis) spat collectors in highly dynamic tidal environments of the Lower Saxonian coast (southern North Sea). Biomol. Eng. 20, 407-411.

722 Widdows J., Bayne B.L., 1971, Temperature acclimation of Mytilus edulis with reference to its energy budget. J. Mar. Biol. Ass. U.K. 51, 827-843.

724 Wilson B., 1968, Survival and reproduction of the mussel Xenostrobus securis (Lam.) (Mollusca-BivalviaMytilidae) in a Western Australian estuary. I. Salinity tolerance. J. Nat. Hist. 2, 307-328.

726 Yamamoto, H., 1995. Marine adhesive proteins and some biotechnological applications. Biotechnol. Genet. Eng. 13, 133-165.

728 Yonge C.M., 1962, On the primitive significance of the byssus in the Bivalvia and its effects in evolution. J. Mar. Biol. Assoc. U.K. 42, 113-125.

730 Young G.A., 1985, Byssus-thread formation by the mussel Mytilus edulis: effects of environmental factors. Mar. Ecol. Prog. Ser. 24, 261-271.

732 Zardi G.I., Nicastro K.R., Mc Quaid C.D., Rius M., Porri F., 2006, Hydrodynamic stress and habitat partitioning between indigenous (Perna perna) and invasive (Mytilus galloprovincialis) mussels: constraints of an evolutionary strategy. Mar. Biol. 150, 79-88.

Zardi G.I., McQuaid C.D., Nicastro K.R., 2007, Balancing survival and reproduction: seasonality of wave action, attachment strength and reproductive output in indigenous Perna perna and invasive Mytilus galloprovincialis mussels. Mar. Ecol. Prog. Ser. 334, 155-163. 


\section{ALR-252v3 - page 21/33}

738 Zardi G.I., Nicastro K.R., Mc Quaid C.D., Erlandsson J., 2008, Sand and wave induced mortality in invasive 740 (Mytilus galloprovincialis) and indigenous (Perna perna) mussels. Mar. Biol. 153, 853-858. 


\section{Figure Legends}

Figure 1. Experimental sites located in Ría de Vigo (NW Spain). San Simón (SS) and Sampaio

(SP) indicate the inner sheltered site and the site at the mouth of river Verdugo flowing into the Ría, respectively.

Figure 2. Individual layout of the mussels on slates for byssus counting.

Figure 3. Field results: (a) Shape and morphology of the mytilids $M$. galloprovincialis and $X$. securis, (b) Shell area (SA) values as a function of mussel size (shell length, SL) for both mytilids. M. galloprovincialis: [SA $=0.0062 \mathrm{SL}^{1.67} \mathrm{r}^{2}=0.94 \mathrm{p}<0.001 \mathrm{n}=35$ ] X. securis: $[\mathrm{SA}=0.0098$ $\left.\mathrm{SL}^{1.43} \mathrm{r}^{2}=0.87 \mathrm{p}<0.001 \mathrm{n}=35\right]$.

Figure 4. Field results: (a) Attachment strength (AS) values as a function of mussel size (shell length, SL) for M. galloprovincialis and $X$. securis in San Simón (SS). M. galloprovincialis: [AS = $0.39 \mathrm{SL}+4.77 \mathrm{r}^{2}=0.65 \mathrm{p}<0.01 \mathrm{n}=9$ ]; $X$. securis: not significant, (b) Attachment strength values as a function of mussel size (shell length) for $X$. securis in both experimental sites: San Simón (SS) and Sampaio (SP), relationships are not significant, (c) Byssus thickness (BT) values as a function of mussel size (shell length, SL) for M. galloprovincialis for both proximal and distal sections of the filaments. proximal: not significant; distal: [BT $=1.78 \mathrm{SL}+19.17 \mathrm{r}^{2}=0.93 \mathrm{p}<0.001 \mathrm{n}=5$ ], (d) Byssus thickness values as a function of mussel size (shell length) for $X$. securis for both proximal and distal sections of the filaments, relationships are not significant.

Figure 5. Laboratory results: (a) Attachment strength values of $M$. galloprovincialis and $X$. securis on slate as a function of flow speed on the slate disposition [ $\mathrm{n}=15$ for each species]. (b) Attachment strength values of $M$. galloprovincialis and $X$. securis on the nylon ropes as a function of flow speed

Figure 6. Laboratory results: Number of byssus threads secreted by $M$. galloprovincialis on slate exposed to different flow speed values.

Figure 7. Laboratory results: Scanning electron micrographs of the proximal and distal surfaces of the byssus secreted by M. galloprovincialis and $X$. securis.

Figure 8. Photographs of the internal anatomy of $M$. galloprovincialis and $X$. securis showing the differences in foot organ size [1 within a circle]. 
794

796

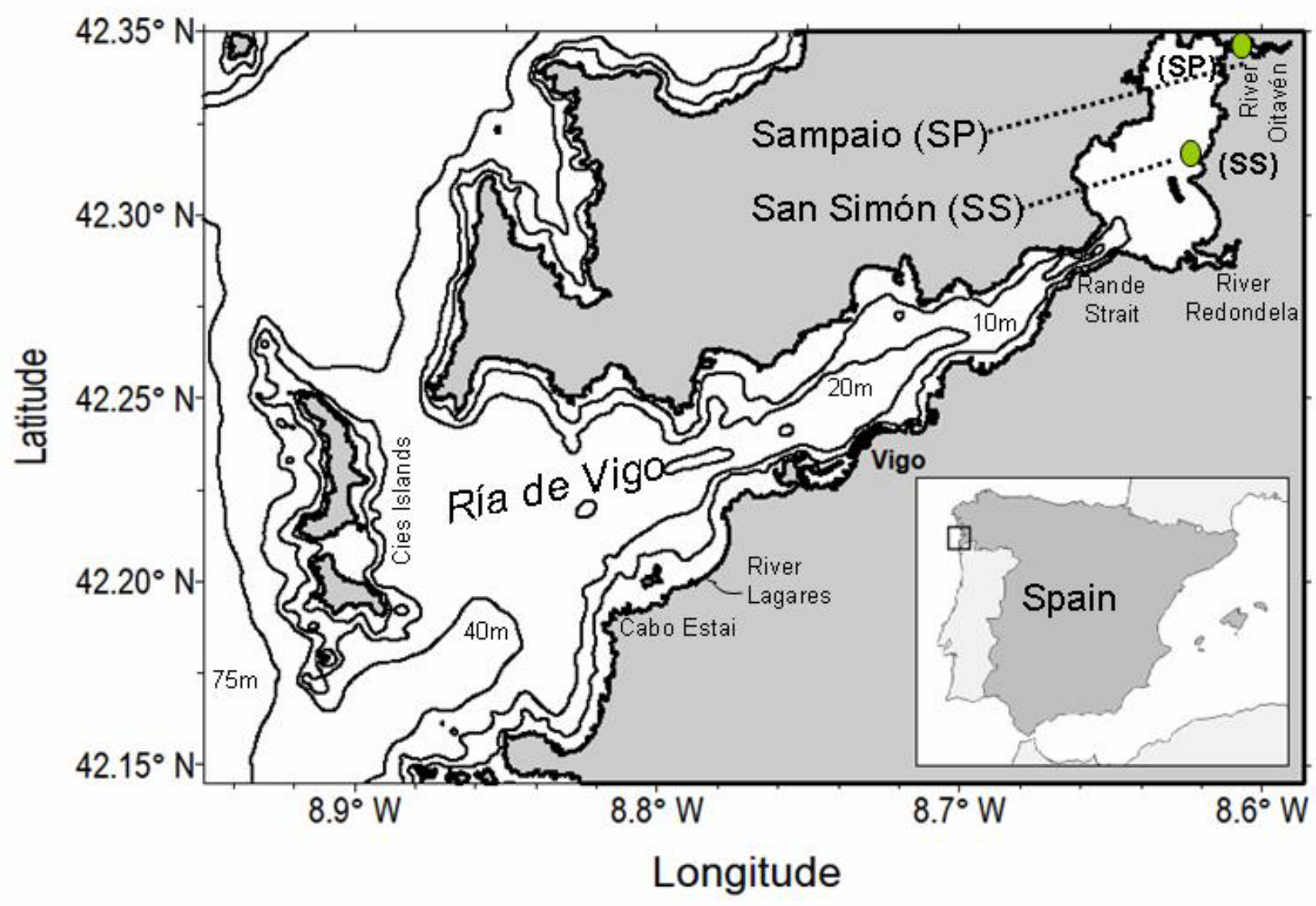


ALR-252v3 - page 24/33

820

822
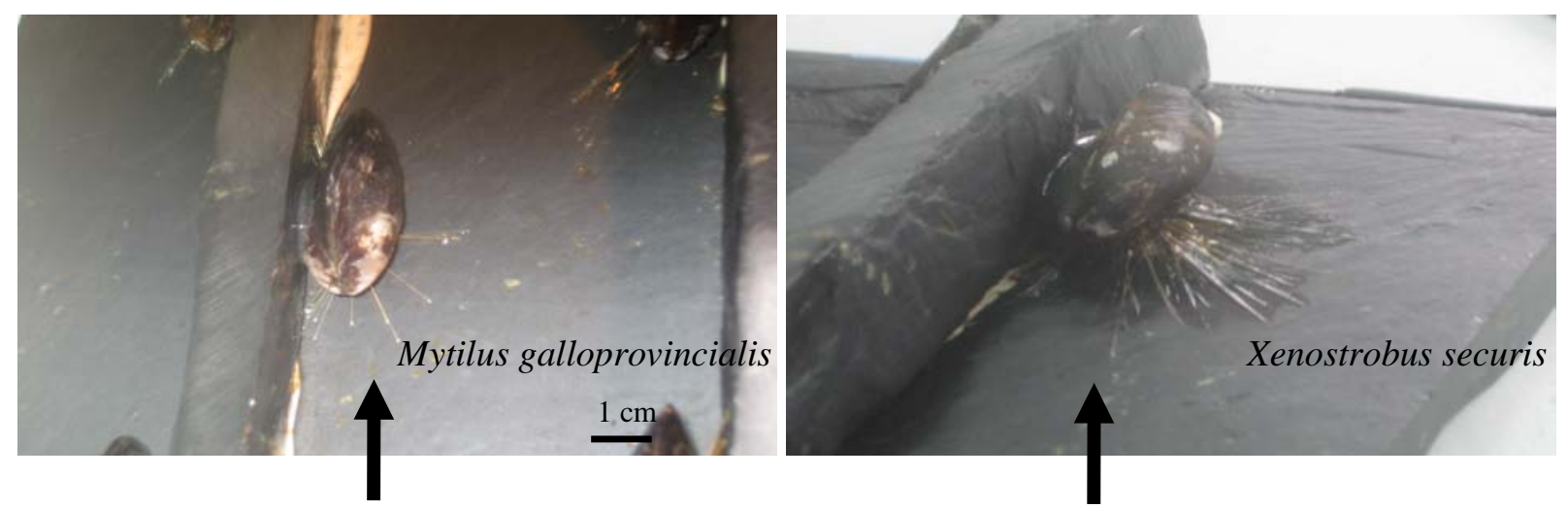

824

flow direction

826

828

830

832

834

836

838

840

842

844

846

848

Figure 2

850

852

854 
ALR-252v3 - page 25/33

a

856

858

Mytilus galloprovincialis

Xenostrobus securis

860
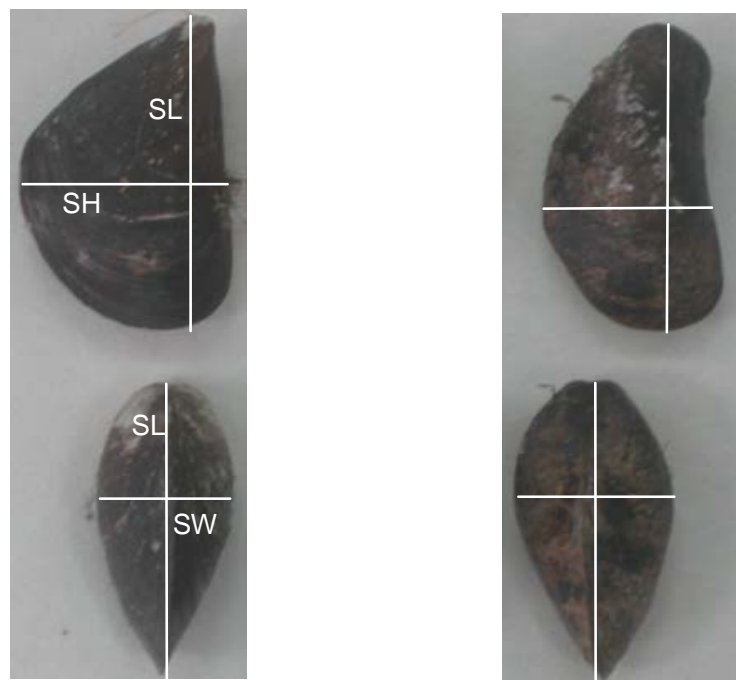

862

864

b

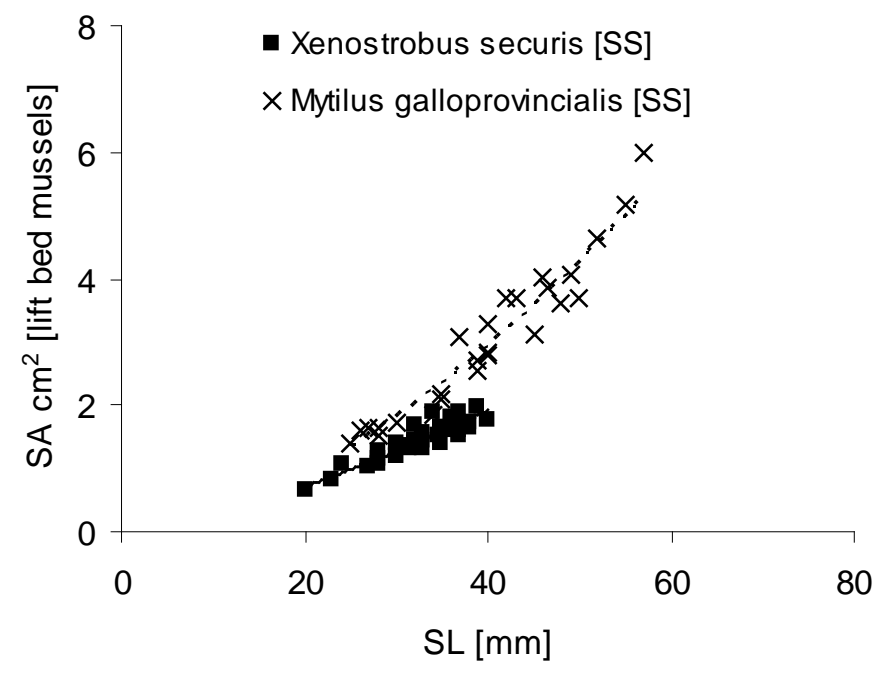

866

868

870

872

Figure 3

874 


\section{ALR-252v3 - page 26/33}

876

878

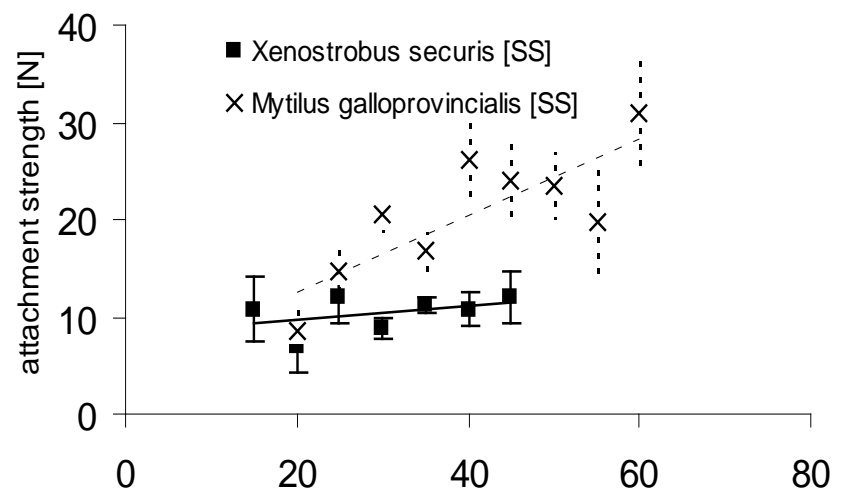

880

882

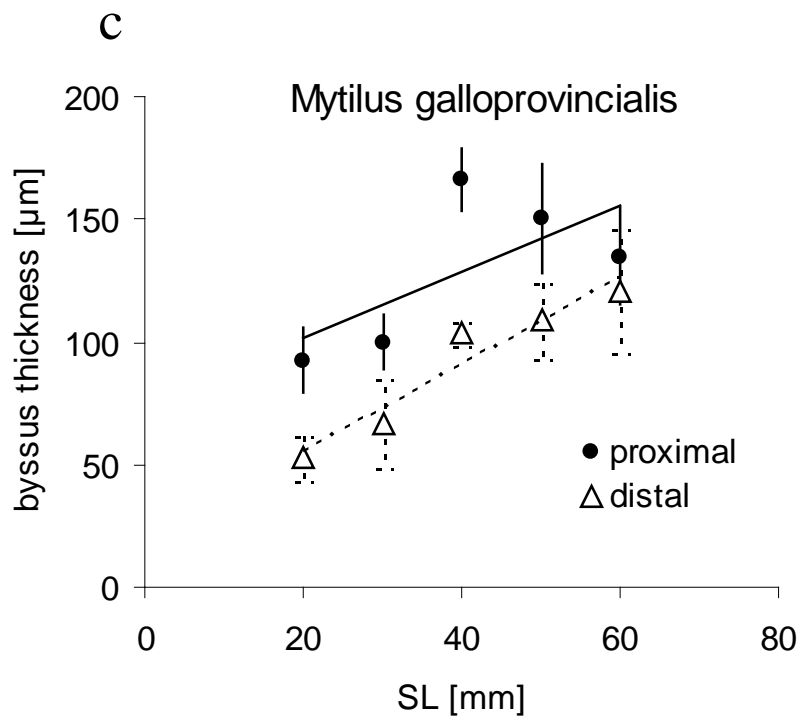

b

San Simón and Sampaio

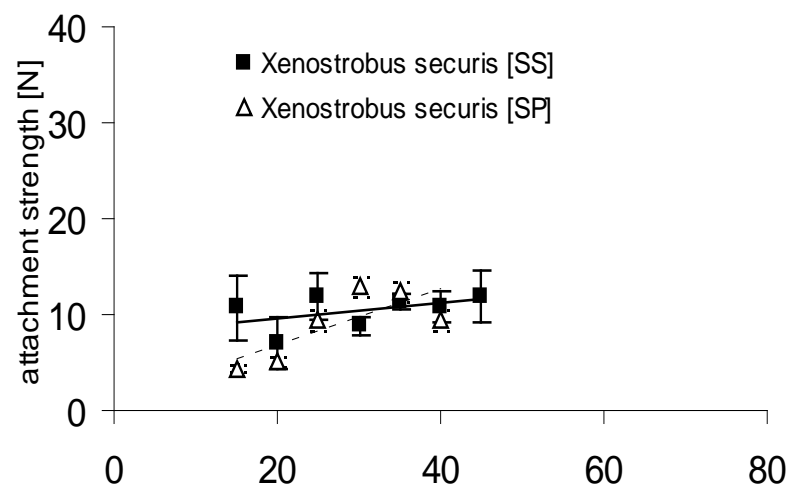

d

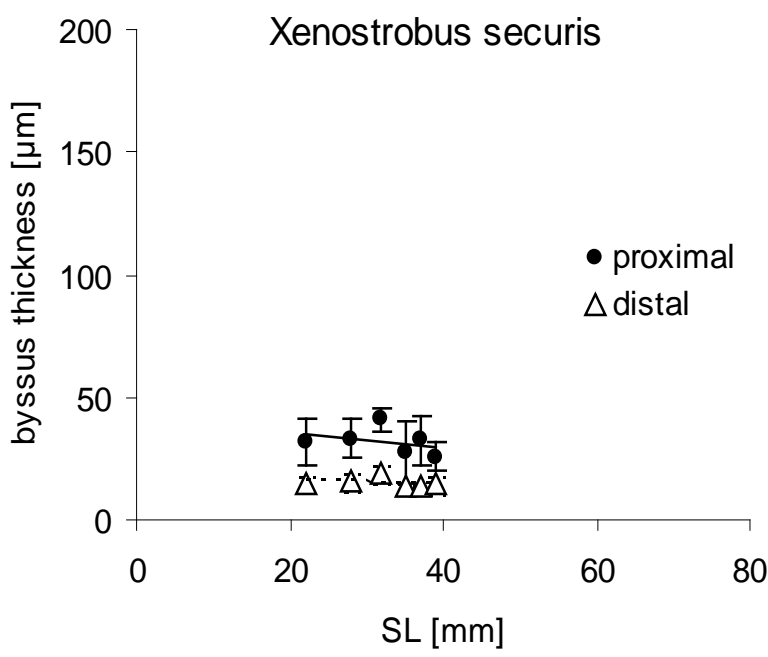

884

886

888

890

892

894

Figure 4

896 
898

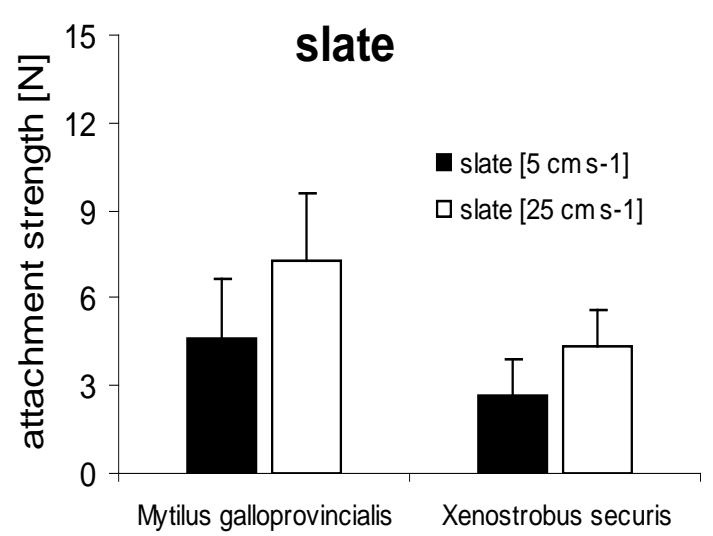

b

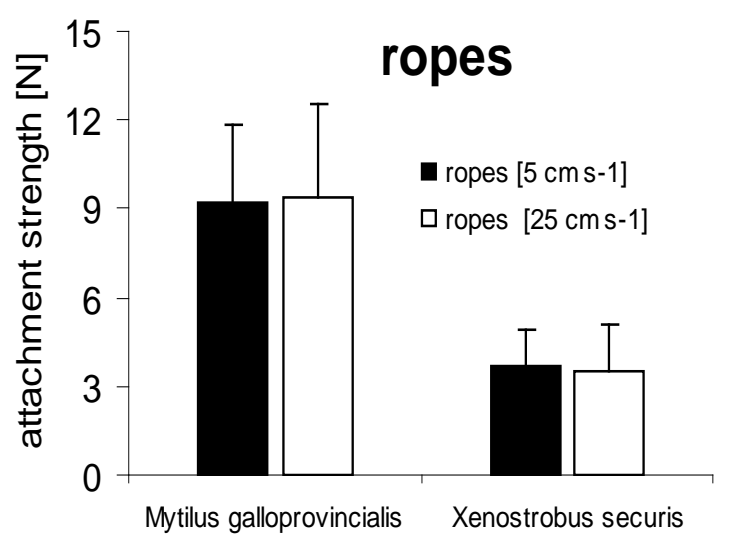

900

902

904

906

908

910

912

914

916

918

920

922

924

926

Figure 5

928

930 
ALR-252v3 - page 28/33

932

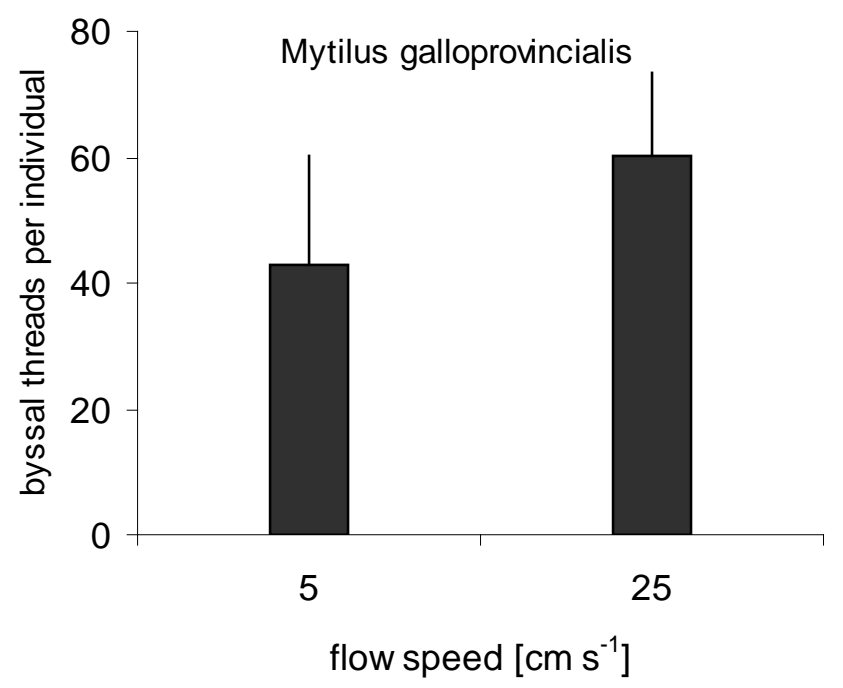

934

936

938

940

942

944

946

948

950

952

954

956

958

960

Figure 6 
ALR-252v3 - page 29/33

962

964

966

Mytilus galloprovincialis

968
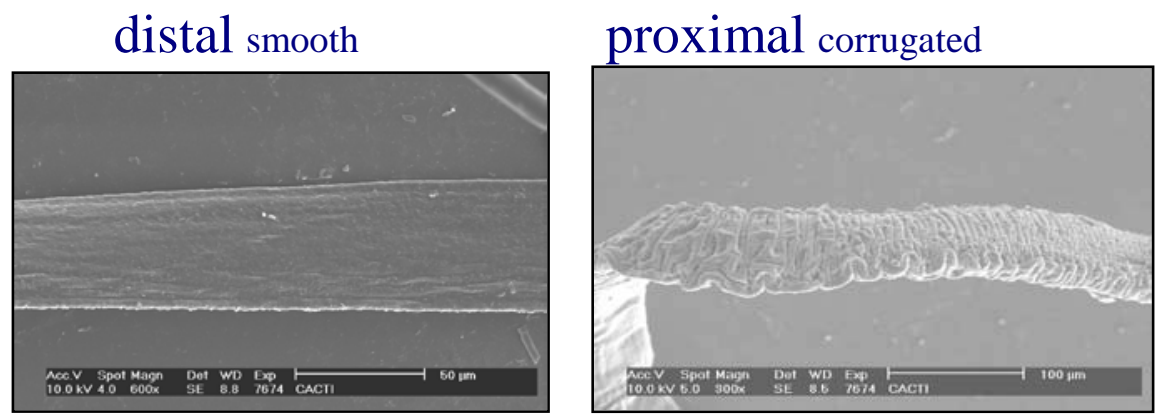

970

972

974

Xenostrobus securis

976

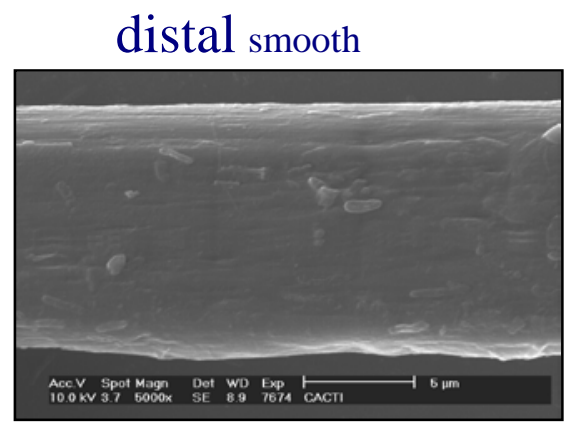

proximal corrugated

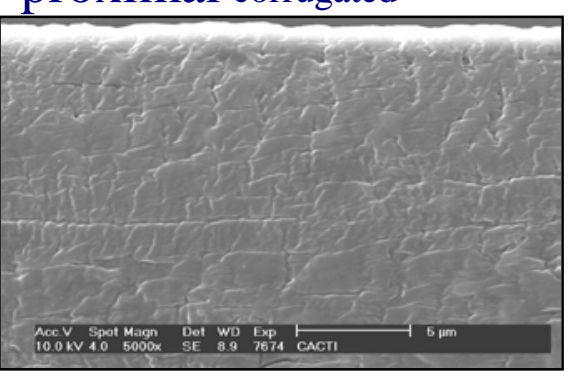

978

980

982

984

986

988

990

992

994

996

Figure 7 


\section{ALR-252v3 - page 30/33}

998

1000

Mytilus galloprovincialis

Xenostrobus securis

1002

1004

1006

1008

1010

1012
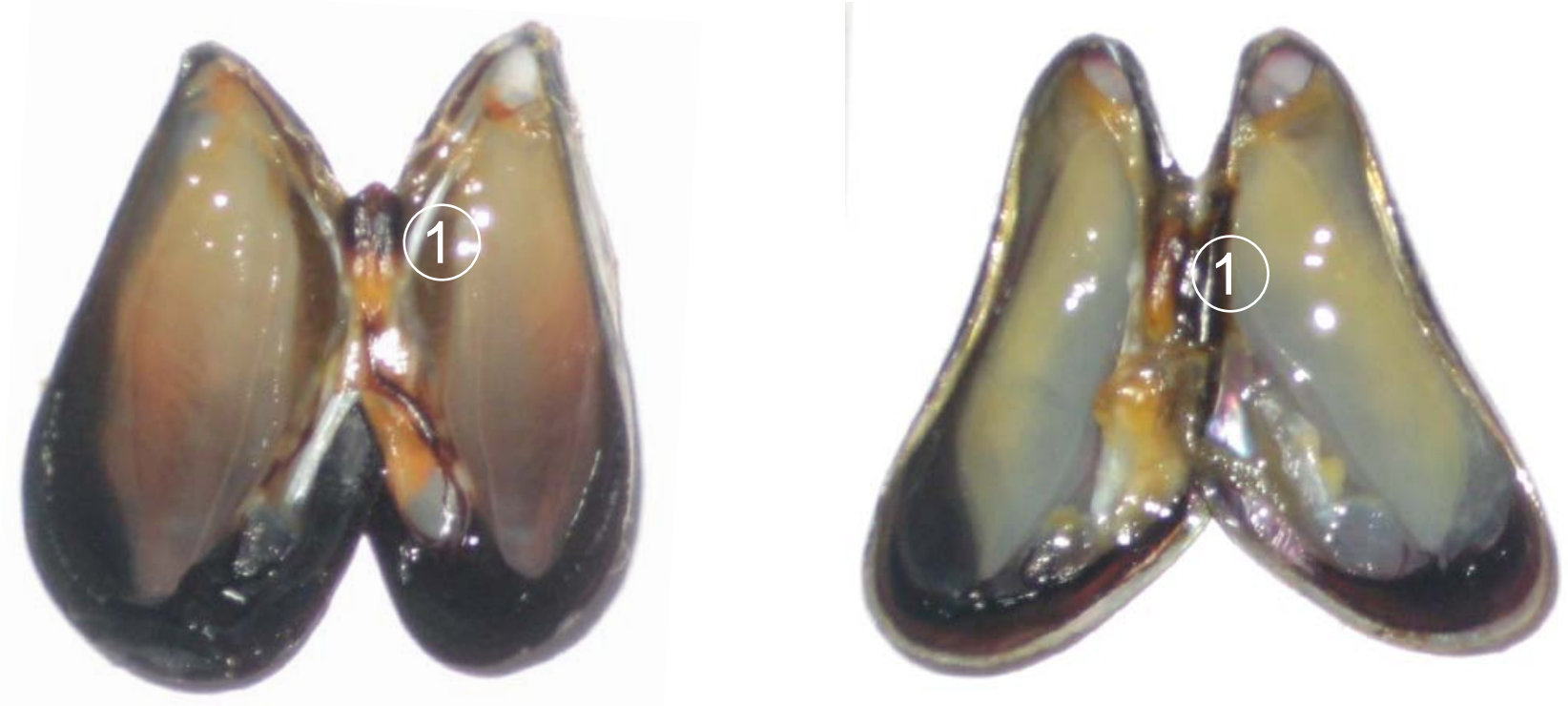

1014

1016

1018

1020

1022

1024

1026

1028

1030

1032

1034

1036

1038

Figure 8 
1042 Table 1. Field: Abiotic parameters of seawater at San Simón (SS) and Sampaio (SP) sites during sampling 1044 (February 2010). Ranges of values include both low and high tides.

\begin{tabular}{llll} 
Sites & temperature $\left({ }^{\circ} \mathrm{C}\right)$ & flow speed $\left(\mathrm{cm} \mathrm{s}^{-1}\right)$ & salinity $(\mathrm{ppt})$ \\
San Simón (SS) & $11.3-13.2$ & $0-2.3$ & $32.0-32.4$ \\
& & & \\
Sampaio (SP) & $9.8-10.8$ & $8.0-123.1$ & $6.2-32.0$ \\
\hline
\end{tabular}




\section{ALR-252v3 - page 32/33}

Table 2. Laboratory results: Byssus thread measurements for the studied mytilids (shell length: $33.0 \pm 2.0 \mathrm{~mm}$ ).

Values are means \pm SD. Statistics presented in the Table were performed for flow speed comparisons in each species independently.

ns: not significant

\section{Mytilus galloprovincialis}

$25 \mathrm{~cm} \mathrm{~s}^{-1}$

thread length (mm)

proximal section (\% whole thread)

proximal thickness $(\mu \mathrm{m})$

distal thickness $(\mu \mathrm{m})$
$12.6 \pm 4.2$

$24.2 \pm 6.2$

$100.4 \pm 23.4$

$71.5 \pm 20.9$

$\begin{array}{lll}13.9 \pm 3.6 & \text { ns } & 10.4 \pm 2.2 \\ 22.6 \pm 6.9 \text { ns } & 6.9 \pm 2.4 \\ 99.9 \pm 20.0 \text { ns } & 28.5 \pm 6.0 \\ 68.7 \pm 16.6 \text { ns } & 14.2 \pm 1.6\end{array}$

\section{Xenostrobus securis}

$5 \mathrm{~cm} \mathrm{~s}^{-1} \quad 25 \mathrm{~cm} \mathrm{~s}^{-1}$


ALR-252v3 - page 33/33 